\title{
Perancangan Sistem Pendataan Penduduk pada Kelurahan Air Itam dengan Object Oriented
}

\author{
Marini \\ ${ }^{1}$ Jurusan Sistem Informasi STMIK Atma Luhur \\ e-mail: arinimarini44@yahoo.co.id
}

\begin{abstract}
Abstrak-Administrasi merupakan Pengelolaan data atau arsip terutama di kelurahan Air Itam yang mana termasuk dalam salah satu pelayanan masyarakat. Rekapitulasi arsip perubahan penduduk sangat penting. Pelaksanaan pelayanan masyarakat yang sebelumnya masih dilakukan secara manual. Dengan Perancangan Sistem pendataan Penduduk ini akan mempermudah pengguna di kelurahan Air Itam dalam mengarsip Data Kependudukan. Tujuan dari penelitian ini adalah untuk menyediakan Sistem Administrasi terkomputerisasi dalam database. Pengolahan data yang dihasilkan dari sistem akan digunakan untuk pendataan penduduk di Kelurahan Air Itam. Dokumen arsip yang berkaitan dengan tujuan peningkatan mutu Administrasi kelurahan Air Itam dan meningkatkan pelayanan publik. Hal ini berbeda dengan sistem manual yang telah digunakan, dengan sistem terkomputerisasi ini risiko kehilangan data dan kerusakan serta untuk menyajikan hasil data lebih rapi. Selain itu, dengan sistem ini, sekertaris akan lebih nyaman dan efisien dalam bekerja karena dapat dengan mudah mengakses informasi tentang perkembangan masyarakat di daerah tanpa kebutuhan untuk menemukan informasi dalam tumpukan kertas.
\end{abstract}

Kata Kunci-Administrasi, Pelayanan Publik, Sistem Administrasi terkomputerisasi

\section{PENDAHULUAN}

$\mathrm{P}$ erkembangan kebutuhan informasi sejalan dengan perkembangan ilmu pengetahuan dan teknologi yang semakin pesat, khususnya ilmu komputer. Dalam hal ini, komputer memegang peranan yang sangat penting sebagai alat bantu dalam pengolahan data. Penggunaan komputer yang dilengkapi dengan program aplikasi yang menunjang akan menghemat waktu, biaya, dan tenaga serta memudahkan dalam menghasilkan informasi berkualitas seperti yang dibutuhkan.

Komputer merupakan serangkaian alat elektronika yang disusun sedemikan rupa sehingga dapat mengolah data menjadi informasi secara cepat dan tepat menurut Yogiyanto [3]. Komputer diciptakan oleh manusia dengan demikian manusialah yang mengoperasikannya, demikian ini komputer

merupakan hal yang dapat membantu segala aktifitas di semua perusahaan atau instansi pemerintah. Adapun sarana yang dimanfaatkan tersebut salah satunya adalah "komputer" yang terdiri dari tiga komponen yang saling terkait antar lain : Perangkat keras (hardware), perangkat lunak (software) serta manusia (brainware).

Dalam konteks sistem informasi, sistem terintegrasi (integrated system) merupakan sebuah rangkaian proses untuk menghubungkan beberapa sistem-sistem komputerisasi dan software aplikasi baik secara fisik maupun secara fungsional. Sistem terintegrasi akan menggabungkan komponen sub-sub sistem ke dalam satu sistem dan menjamin fungsi-fungsi dari sub sistem tersebut sebagai satu kesatuan sistem.

Sistem terintegrasi merupakan tantangan menarik dalam software development karena pengembangannya harus terus mengacu pada konsistensi sistem, agar sub-sub sistem yang sudah ada dan tetap dimanfaatkan secara operasional masih tetap berfungsi sebagaimana mestinya baik ketika proses mengintegrasikan sistem maupun setelah terintegrasi. Tantangannya adalah bagaimana merancang sebuah mekanisme mengintegrasikan sistem-sistem tersebut dengan paling minimal bahkan jika diperlukan, tidak harus melakukan refactoring atau re-developing lagi sistem-sistem yang sudah ada.

Sistem pengolahan data penduduk pada Kantor Kepala Desa Air Itam masih bersifat manual dengan menggunakan Buku besar. seperti pencatatan data penduduk, pendaftaran data penduduk, proses data penduduk yang tidak didokumentasi dengan baik dan dapat mengakibatkan data menjadi tidak vailid, yang dalam pembuatannya mempunyai tingkat efektifitas serta efisiensi yang tergolong lemah. Maka akan sangat berpengaruh dalam produktivitas kerja perusahaan itu sendiri.

Batasan masalah dalam Analisa Sistem administrasi ini hanya pada Proses Pendataan Penduduk.

Tahap perancangan sistem adalah merancang sistem secara rinci berdasarkan hasil analisa sistem yang ada, sehingga menghasilkan model yang ada, sehingga menghasilkan model sistem baru yang diusulkan, dengan disertai rancangan database dan spesifikasi program.

Alat-alat yang digunakan pada tahap perancangan sistem informasi ini antara lain sebagai berikut :

a. Logical Record Structure (LRS)

LRS terdiri dari link-link (hubungan) diantara tipe record. Link ini menunjukkan arah dari satu tipe record lainnya.

b. Spesifikasi Basis Data

Spesifikasi basis data digunakan untuk menjelaskan tipe data yang ada pada LRS secara detail.

c. Sequence Diagram

Menjelaskan interaksi obyek yang disusun dalam suatu urutan waktu. Urutan waktu yang dimaksud adalah urutan kejadian yang dilakukan oleh seorang aktor dalam menjalankan suatu system. 


\section{URAIAN PENELITIAN}

\section{A. Konsep Dasar Sistem}

Menurut Tata Sutabri [6] Terdapat dua kelompok pendekatan didalam pendefinisian sistem, yaitu kelompok yang menekankan pada prosedur dan kelompok yang menekankan pada elemen atau komponennya. Pendekatan yang menekankan pada prosedur mendefinisikan sistem sebagai suatu jaringan kerja prosedur-prosedur yang saling berhubungan, berkumpul bersama-sama untuk melakukan suatu kegiatan atau untuk menyelesaikan suatu sasaran tertentu. Sedangkan pendekatan sistem yang lebih menekankan pada elemen atau komponen medefinisikan sistem sebagai kumpulan elemen yang berintraksi untuk mencapai suatu tujuan tertentu. Kedua kelompok definisi ini adalah benar dan tidak bertentangan. Yang berbeda adalah cara pendekatannya.

\section{B. Analisa Sistem Berorientasi Obyek}

\section{Activity Diagram}

Menurut Munawar [4] Activity Diagram adalah teknik untuk mendeskripsikan logika prosedural, proses bisnis dan aliran kerja dalam banyak kasus. Activity diagram mempunyai peran seperti halnya flowchat, akan tetapi perbedaannya dengan 30 flowchat tidak bias menurut Munawar [4].

\section{Use Case Diagram}

Use case diagram mengambarkan kebutuhan sistem dari sudut pandang user. Digunakan untuk menggambarkan hubungan antara internal sistem dan eksternal sistem atau hubungan antara use case dan actor.

\section{Logical Record Struktur (LRS)}

LRS digambarkan oleh kotak persegi panjang dan dengan nama yang unik. File record pada LRS ditempatkan dalam kotak. LRS terdiri dari link-link diantara tipe record lainnya, banyak link dar LRS yang diberi nama oleh field-field yang kelihatan pada kedua link tipe record.

\section{Sepesifikasi Basis Data}

Basis data merupakan kumpulan dari data yang saling berhubungan satu dengan yang lain dan tersimpan diluar komputer serta digunakan perangkat lunak ( software) tertentu untuk memanipulasinya menurut Imam [2]. Sedangkan sistem berbasis data adalah suatu sistem penyusunan dan pengelolaan record-record dengan menggunakan komputer dengan tujuan untuk menyimpan atau merekam serta melihat data operasional lengkap pada sebuah organisasi, sehingga mampu menyediakan informasi yang diperlukan untuk kepentingan proses pengambilan keputusan.

\section{HASIL IMPLEMENTASI}

\section{A. Uraian Prosedur}

Prosedur yang dilakukan dalam analisa sistem informasi pengolahan data penduduk pada kantor kepala desa Air Itam adalah sebagai berikut:

\section{Proses Pendataan Penduduk}

Pada proses pencatatan warga, masing-masing Ketua RW mencatat data setiap keluarga di buku data penduduk berdasarkan Kartu Keluarga kemudian setelah Ketua RW mencatat data penduduk, Ketua RW menyerahkan data penduduk ke Sekdes, kemudian Sekdes mencatat data pendudk tersebut di buku data penduduk, setelah data tersebut ditulis dibuku penduduk kemudian diketik dan disimpan dalam komputer.

a) Proses Pendataan Penduduk

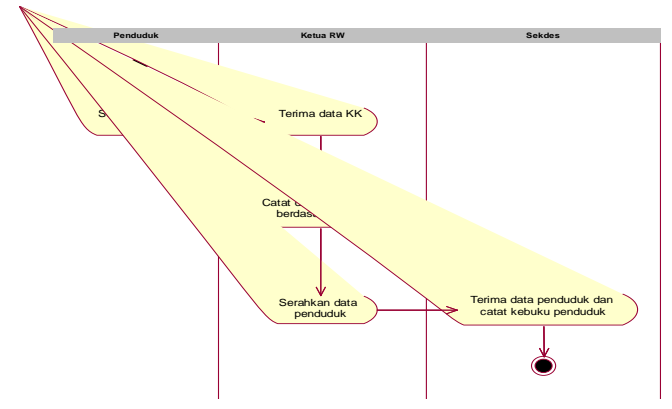

Gambar 1. Activity Diagram Proses kegiatan pendataan penduduk yang dilakukan oleh sekretaris kepala desa.

b) Use case Data penduduk

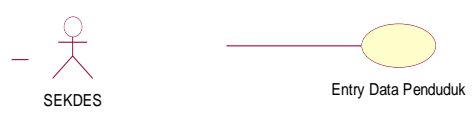

Gambar 2. Use case diagram data penduduk yang dilakukan sekretaris desa untuk menginput data penduduk.

c) LRS

\begin{tabular}{|l||l|l|}
\hline \multicolumn{1}{|c|}{ Penduduk } & \multicolumn{1}{c|}{ SK } \\
\cline { 1 - 1 } Nik & \multicolumn{1}{|c|}{ Terima } & \\
Nm_lengkap & No_SK \\
Tmpt_lahir & Nik & TgI_SK \\
Tgl_lahir & No_SK & Hr_lahir \\
Jengkel & Status & Tgl_lahir \\
Agama & KWA & Pukul \\
Status & Keturunan & Tmpt_lahir \\
Pddk_akhir & kebangsaan & Jns_Kelamin \\
Pekerjaan & & Nm_bayi \\
Alamat & & Nik_pelaporSK \\
\hline
\end{tabular}

Gambar 3. Hubungan relasi antara field penduduk direlasikan ke field terima dan dihubungkan ke relasi field SK 
d) Tabel Penduduk

Tabel 1

Tabel Penduduk

\begin{tabular}{|l|l|l|l|l|}
\hline NIK & Nm_lengkap & Tmpt_lahir & Tgl_lahir & Jengkel \\
\hline PK & & & & \\
\hline & & & & \\
\hline
\end{tabular}

\begin{tabular}{|l|l|l|l|l|}
\hline Agama & Status & Pddk_akhir & Pekerjaan & Alamat \\
\hline & & & & \\
\hline & & & & \\
\hline
\end{tabular}

Tabel 2

Tabel Terima

\begin{tabular}{|c|c|c|c|l|l|}
\hline NIK & No_SK & Status & KWA & Keturunan & Kebangsaan \\
\hline FK & FK & & & & \\
\hline \multicolumn{2}{|c|}{ PK } & & & & \\
\hline
\end{tabular}

Tabel 3

Tabel SK

\begin{tabular}{|c|l|l|l|l|l|}
\hline No_SK & Tgl_SK & Hr_lahir & Tgl_lahir & $\begin{array}{l}\text { Puku } \\
1\end{array}$ & $\begin{array}{l}\text { Tmpt_l } \\
\text { ahir }\end{array}$ \\
\hline PK & & & & & \\
\hline & & & & & \\
\hline
\end{tabular}

\begin{tabular}{|l|l|c|}
\hline Jns_Kelamin & Nm_bayi & NIK_pelaporSK \\
\hline & & FK \\
\hline & & \\
\hline
\end{tabular}

e) Rancangan Layar Entry Data Penduduk

\begin{tabular}{|l|l|}
\hline \multicolumn{1}{|c|}{ FORM ENTRY DATA PENDUDUK } \\
NIK & ENTRY DATA PENDUDUK \\
Nama Lengkap & $<<$ Auto $>>$ \\
Tempat Lahir & $<<$ Input $>>$ \\
Tanggal Lahir & $<<$ Input $>>$ \\
Jenis Kelamin & $<<$ Pilih $>>$ \\
Agama & $<<$ Pilih $>>$ \\
Status & $<<$ Pilih $>>$ \\
Pendidikan Terakhir & $<<$ Pilih $>>$ \\
Pekerjaan & $<<$ Pilih $>>$ \\
\hline
\end{tabular}

Gambar 4. Untuk menginput data penduduk baru dan mengupdate data penduduk f) Rancangan Layar Entry Surat Kelahiran

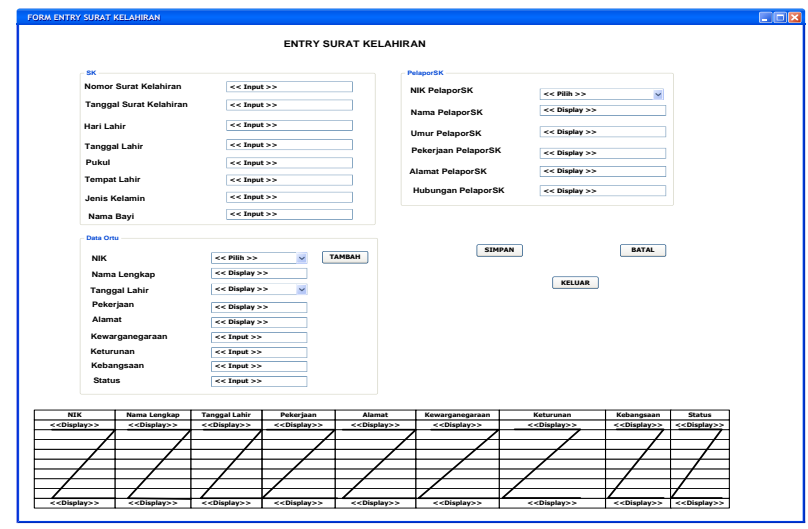

Gambar 5. Form yang digunakan untuk menginput data surat kelahiran

g) Rancangan Layar Cetak Laporan Rekapitulasi Data

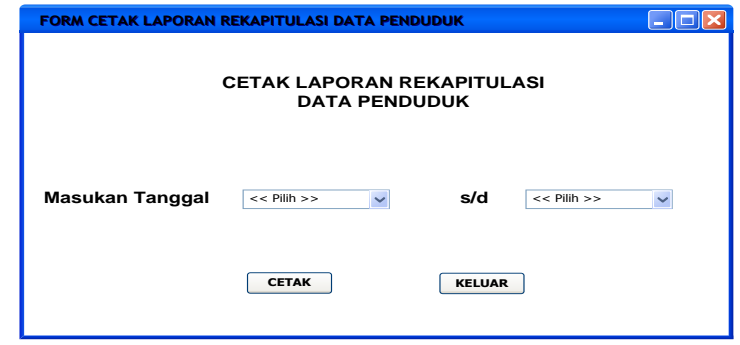

Gambar 6. Form untuk mencetak Laporan Rekapitulasi Data Penduduk

h) . Rancangan Layar Cetak Laporan Keterangan Penduduk

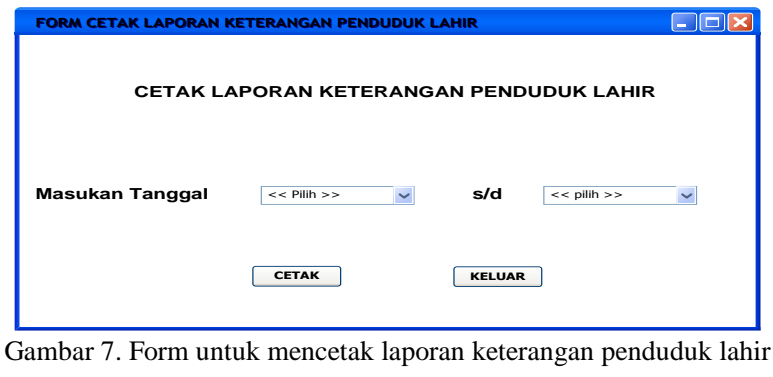

i) Sequence Diagran Entry Data Penduduk

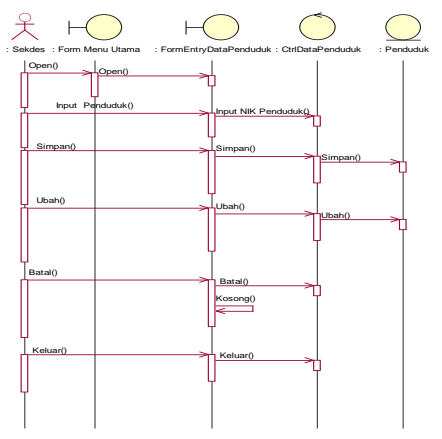

Gambar 8. Sequence Diagram Data Penduduk 


\section{j) Sequence Diagram Entry Surat Kelahiran}

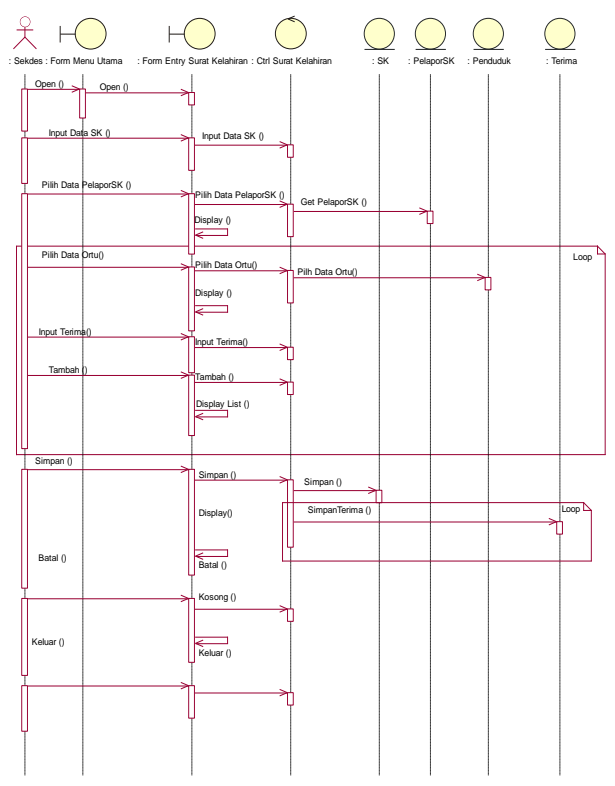

Gambar 9. Sequence Diagram Surat Kelahiran

k) Sequence Diagram Cetak Laporan Rekapitulasi Data

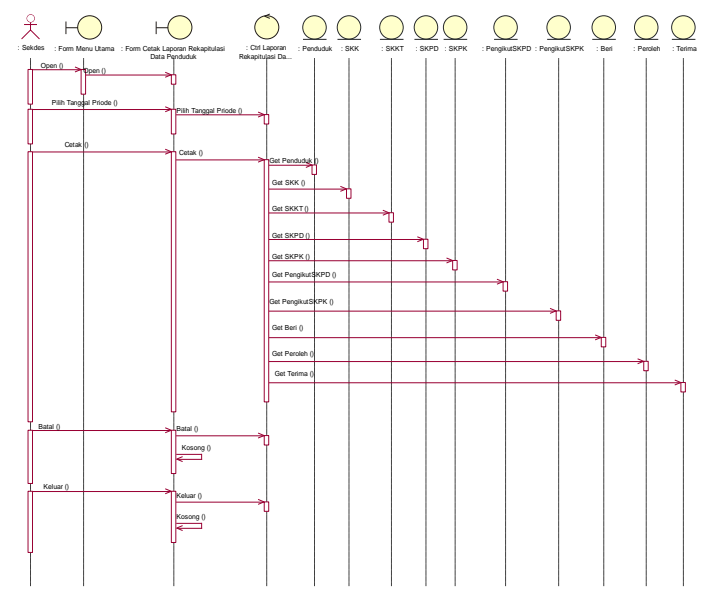

Gambar 10. Sequence Diagram Cetak Laporan Rekapitulasi Data Penduduk

1) Sequence Diagram Cetak Laporan Keterangan Penduduk

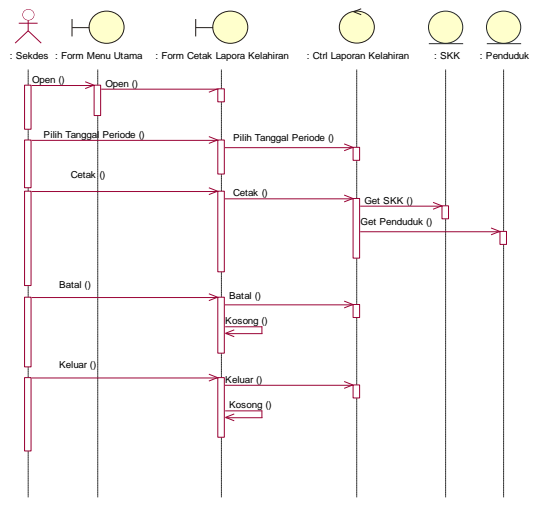

Gambar 11. Sequence Diagram Cetak Laporan Keterangan Penduduk Lahir

\section{KESIMPULAN}

Setelah melakukan analisis terhadap permasalahan pada Sistem Informasi pendataan Penduduk Pada kelurahan Air itam dan mencoba memberikan alternatif solusi dengan membuat Sistem Informasi pendataan penduduk, maka dapat ditarik suatu kesimpulan dan memberikan saran untuk perbaikan dari kinerja sistem.

Berdasarkan dari uraian Sistem Informasi Pengolahan Data Penduduk diatas, maka dapat diambil kesimpulan sebagai berikut :

1. Dengan dibuatnya sistem informasi pengolahan data penduduk agar dapat membantu bagian Sekdes dalam meningkatkan efektifitas dan efisiensi data kependudukan.

2. Dengan sistem informasi pengolahan data penduduk ini, mempermudah dalam proses pengolahan data penduduk dan pencarian data, karena data-data yang berkaitan dengan pengola han data penduduk tersimpan rapi di dalam sebuah database.

\section{DAFTAR PUSTAKA}

[1] Hariyanto, B. "Rekayasa system berorientasi Objek", Bandung: Informatika Bandung.(2004)

[2] Imam. "Membuat Database dengan Microsoft Access." Bandung: Informatika, (2008).

[3] Jogiyanto. "Sistem Teknologi Informasi" .Yogyakarta : Andi, (2003)

[4] Munawar. "Pemodelan UML Berorientasi Objek.", Jakarta:Andy Jogyakarta, (2005).

[5] Supardi, Y. "Sетиa Bisa Menjadi Programmer VB 6 Hingga VB 2008 Basic." Jakarta: PT. Elex Media Komputindo, (2011).

[6] Sutabri, T. Analisa Sistem Informasi. Jakarta : penerbit Andi, (2012). 